THE ORGANISATION OF INDUSTRIAL EDUCATION

$\mathrm{THE}$ following is the letter by Prof. Huxley to which reference is made in our leading article (p. 482):-

"When a statesman of Lord Hartington's authority concurs with and enforces the opinions I ventured to express some little time ago, I have every reason for private and personal satisfaction. But the circumstance has a public importance as evidence that our political chiefs and leaders are giving their serious attention to those social questions which lie far above the region of party strife, and are of infinitely greater moment than the topics which ordinarily absorb the attention of politicians.

"The organisation of industrial and commercial education is not the least of these great problems. That it has to be solved, under penalty of national ruin, proves to be no mere alarmist fancy, but the belief of an experienced man of affairs, whose imperturbable coolness and strong common-sense are proverbial.

"It is an interesting question for us all, therefore, How do we stand prepared for the task thus imperatively set us? My conviction is that we are in some respects better off than most people imagine, in others worse. I conceive that two things are needful : on the one hand, a machinery for providing instruction and gathering information; on the other hand, a machinery for catching capable men wherever they are to be found and turning them to account. Now, I apprehend that both these kinds of machinery are to be found, though in a fragmentary and disconnected condition, in several organisations which, though independent, supplement one a nother.

"The first of these is that of the School Boards, which provide elementary education, and sometimes, though too rarely, have at their disposal scholarships by which capable scholars can attain a higher training. The second is the organisation of the Department of Science and Art. The classes, now established all over the country in connexion with the Department, not only provide elementary instruction, accessible to all, but offer the means whereby the pick of the capable students may obtain in the schools at South Kensington as good a higher education in science and art as is to be had in the country. It is from this source that the supply of science and art teachers, who in turn raise the standard of elementary instruction, is derived. The third organisation is that of the technical classes connected with the City and Guilds Institute, or with the Society of Arts, or with provincial Universities and Colleges, which provide special technical instruction for those who have, or ought to have, already acquired the elements of scientific and artistic knowledge in the science and art classes.

"A fourth organisation for the advancement of the interests of industry and commerce, of the nature of that which I imagined it was the intention of the founders of the Imperial Institute to create, and such as is, I believe, now actually in course of creation in the City of London, will complete the drill-grounds of the army of industry, and, so far as I can judge, omit nothing of primary importance. But, leaving the last aside as still in the embryonic condition, these excellent organisations are all mere torsos, fine--but fragmentary.

"The ladder from the School Boards to the Universities, about which I dreamed dreams many years ago, has not yet acquired much more substantiality than the ladder of Jacob's vision.

"The Science and Art Department has done, and is doing, admirable work, which I regret to see more often made the subject of small and carping criticism than of the praise which is its due. I trust it may not be diverted from efficiently continuing that work by having duties for which it is unfit forced upon it. That which the Department needs, in my judgment, is nothing but the means of doing that which Commission after Commission, Royal and departmental, have declared to be its proper business.

"As Dean of the Normal School I may be permitted to declare that it is impossible for us to perform the functions allotted to us unless the recommendations made by impartial and independent authority are carried into effect.

"The school exists, and common-sense surely suggests either make it efficient or abolish it. The alternative of abolition is not likely to be adopted, as that step would be equivalent to striking the keystone out of the edifice of scientific instruction for the masses of the people which it has taken a quarter of a century to raise, and which is the essential foundation for any sound system of technical education. The alternative of efficiency means spending a few thousand pounds on additional buildings; but the guardians of the national purse do not seem to feel the force of the adage about "spoiling a ship for a halfpennyworth of tar.'

"The state of affairs in regard to that which ought to be the centre of our system of technical education is nearly the same. The Central Institute is undoubtedly a splendid monument of the munificence of the City. But munificence without method may arrive at results indistinguishably similar to those of stinginess. I have been blamed for saying that the Central Institute is 'starved.' Yet a man who has only half as much food as he needs is indubitably starved, even though his short rations consist of ortolans and are served up on gold plate. And I have excellent authority for saying that little more than one-half of the plan of operations of the Institute, drawn up by the Committee of which I was a member, has been carried out, or can be carried out, if the funds allotted for the maintenance of the Institute are not largely increased. At the same time, the Institute is doing all that could be rationally expected of it. Some of the guilds and many provincial towns are making admirable provision for elementary technical education. Such work, in my judgment, ought to be left to local administrators, whatever aid it may be thought desirable to give them. But the local schools should be brought into relation with the Central Institute, and this should be put upon such a footing as to subserve its proper purpose of training teachers and giving higher technical instruction.

"Economy does not lie in sparing money, but in spending it wisely. And it is, to my mind, highly necessary that some man or body of men, whom their countrymen trust, should consider these various organisations as a whole and determine the manner in which they should be correlated and in which it is desirable that the resources, public and private, which are available should be distributed among them.

"Lord Hartington has many claims on the gratitude and respect of his countrymen. I venture to express the wish that he would add to them by taking up this great work of organising industrial education and bringing it to a happy issue."

\section{AUGUST WILHELM EICHLER}

$\mathrm{THE}$ death of Dr. August Wilhelm Eichler, briefly announced in a previous number, is a great loss to botanical science, and especially to systematic botany. Year by year we are losing men of wide and consequently sound knowledge of plants without their places being adequately filled. We have doubtless arrived at a stage in botany where specialists are necessary ; yet we venture to assert that men of general attainments are better qualified than specialists, in a narrow sense, for the head of large botanical establishments, such as the one over which the late Dr. Eichler presided, and which greatly extended its reputation during the nine years he was Director. 
Dr. Eichler was barely forty-eight years of age, but before entering upon the absorbing duties connected with the University and Botanic Garden of Berlin he had already made a name as a.botanical author.

For some years he was assistant to Von Martius at Munich, and succeeded him as editor of the colossal "Flora Brasiliensis," now nearly completed. This was in I 868 , but he had previously been a considerable and excellent contributor to this work, having elaborated several difficult families in a masterly manner. The work by which he is more generally known is the "Bluithendiagramme," in which he admirably illustrates and explains the morphology and organogeny of the Phanerogamia. His labours were chiely in the direction of morphology. His continued careful study of the female lower of the Coniferæ may be regarded as having finally settled the homologies of the different elements of the inflorescence of that family. One of his later contributions to science, if not his last, is entitled "Zur Entwickelungsgeschichte der Palmenblätter," in which the author fully elucidates the development of the various types of leaf in the Palmæ.

As a lecturer Dr. Eichler was exceedingly popular and successful; and he was regarded as an able administrator of the Botanic Garden. He was successively Professor of Botany at Munich, Gratz, Kiel, and Berlin, having been appointed to the last post in 1878 . Two years later, "at the comparatively youthful age of thirty. nine," he was chosen a member of the Berlin Academy of Sciences; and in $188 \mathrm{I}$ he was elected Foreign Member of the Linnean Society of London. He was also honorary and corresponding member of many other learned societies; and all who knew him, however slightly, will join in regretting his early death.

\section{NOTES}

BARON EgGERS, commissioned by Dr. Urban and assisted by the Royal Academy of Sciences of Berlin, is about to undertake the botanical investigation of the hitherto unexplored higher mountains of St. Domingo. The specimens collected for distribution will be arranged (under corresponding numbers) in two series. One will consist only of species which have not yet been distributed in Baron Eggers' West Indian collections; the other and larger series will include everything except the commonest tropical species. The first-named series will be disposed of at forty shillings per century, the latter at thirty shillings. Dr. J. Urban, assisted by other systematists, will determine the collections and receive the names of subscribers. As the expense and difficulty of transit in the island must limit the number of collections for sale, early application to Dr. Urban is desirable. Dr. Urban's address is Friedenau, bei Berlin.

A Conversazione given by the Council of the City and Guilds of London Institute was held at the Central Institution, Exhibition Road, on Wednesday evening, the 16 th inst., and was attended by about $\mathrm{I} 300$ visitors, Lord Selborne received the guests. A large number of interesting objects of scientific and artistic interest were exhibited, and during the evening demonstrations were given by the Professors in the various departments, as well as by several gentlemen who are associated with the work of the Institute.

ON the $15^{\text {th }}$ inst. a meeting was held at Grimsby to consider the expediency of establishing there an Institution for Technical Education with regard to Fish and Fisheries, and a Marine Fish-Culture Station. Mr. W. Oldham Chambers, Secretary of the National Fish-Culture Association, pointed out to the meeting the advantages of the proposed Station and Institute. Resolutions in support of the scheme were unanimously adopted, and an influential local Committee was appointed to further the object in view. Letters have been received from the various Fish Trade Associations and other bodies, heartily approving of the undertaking. The Manchester, Sheffield, and Lincolnshire Railway Company are prepared to grant a site for the Institute, and to erect a building, free of cost, at Cleethorpe, near Grimsby.

We are sorry to see that the income of the Mason Science College, Birmingham, during the year ending "Founder's Day," February 23, fell short of the expenditure by the sum of I646l. After deducting what may be termed extraordinary expenditure, there remained a deficiency of $1074 l$. The Council, in their last report, remind the Trustees that the annual deficits, which since $188 \mathrm{I}$ have been charged against the accumulated surplus, have now reduced this fund to the sum of I4I9l, and that the estimates for the current financial year anticipate that the balance of the fund will be required. It is not creditable to the well-off citizens of Birmingham that an institution capable of doing great work for their town and district should have to meet these constantly recurring deficiencies.

THE spring meeting of the Institution of Mechanical Engineers, under the presidency of $\mathrm{Mr}$. E. H. Carbutt, will take place on Monday, May 16, and the following day. On Tuesday, May 17 , the Duke of Cambridge will dine with the members of the Institution.

IN order to determine between the rival sites for the Sedgwick Memorial Museum at Cambridge, and at the same time advance the chances of proceeding early with a portion at least of the building, the Council of the Senate propose to submit a grace next term to settle the question of site. The grace will take the form of authorising negotiations with Downing College for a site opposite the old Botanic Garden. If this be rejected, the latter affords the only practicable site.

Miss Gordon has presented to the Museum of the Royal Gardens, Kew, the collections and drawings made by her late brother, General Gordon, illustrative of the Coco de Mer (Lodoicea seychellarum), a palm peculiar to the Seychelles, and remarkable, among other things, for possessing the largest known seed in the vegetable kingdom. The seeds are well known in European museums. One amongst General Gordon's specimens is a model which he had made of the fruit in its mature state, before the external fibrous but perishable husk had become detached. Some of the specimens are placed, with others already possessed by Kew, in No. 2 Museum The rest will be shown, with the dra wings made by his own hand, in No. 3 Museum.

THE Cambridge University Local Examination Report for the past year states that in zoology and physiology the answers showed very inefficient teaching. Botany is somewhat better done; but many senior candidates had not been taught the use of floral diagrams. In physical geography, while the answering was generally good, many had used antiquated text-books. Chemistry was fairly done, the candidates choosing, out of the alternative questions, the practical rather than the theoretical. Qualitative analysis was well done, both by seniors and juniors. The seniors showed general ignorance about the laws of multiple proportion, and combination by volume. Heat was badly done by both seniors and juniors. Many seemed never to have read any text-book, and to have presented themselves on the strength of a few isolated facts. Statics was very unequally mastered. There was better acquaintance with the mathematical than with the practical part of the subject. Electricity (senior subject) had not been studied seriously enough to warrant its inclusion in the examination. The mathematical suljects of the examination are reported on much more favourably. 